\title{
Roel Bowkamp and Sonja Bowkamp in collaboration with Clara Bartelds (2014). Blizu doma [Close to Home]. Ljubljana: Znanstvena založba Filozofske fakultete, Pedagoška fakulteta, Inštitut za družinsko terapijo, 386 pp. ISBN 978-961-237-650-5.
}

Reviewed by NinA MEŠL

The publication of this book by Dutch authors Roel Bowkamp and Sonja Bowkamp in the Slovenian sphere contributes valuable new knowledge about processes of support and help to families. The authors, who are the founders of the Kempler Institute in the Netherlands, have trained new generations of gestalt experiential family therapists in Slovenia for more than two decades. However, their work, now translated into Slovenian, reaches beyond psychotherapy and family therapy, as the book opens topics relevant to the diverse professions involved with people who need help at

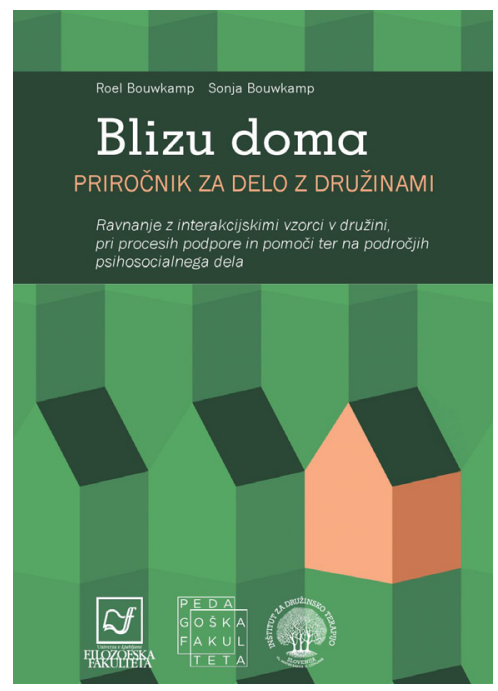
some point in their lives. The book is also welcome for the lay public, as readers can find answers to the many challenges faced in everyday personal life.

There are some points of emphasis that can be considered as particular strengths of the book. Throughout, the authors take a clear professional stance on collaboration with the family and others involved who can contribute to the desired outcomes. In this way, the work surpasses the often dominant way of thinking and acting when people need help. Although knowledge of systems theory entered the helping professions several decades ago, working with individuals is still rooted in everyday practice (the authors present research results according to which 85 percent of cases within the process of help and support deal with individual contacts, while only 3 percent deal with the family (p. 204)). The authors claim that professionals may choose to work with individuals because it seems easier (p. 203), but they also offer a clear invitation to move forward: "it is not true that we do not dare because things are difficult, but things become difficult, because we do not dare" (ibid.). 
The authors draw attention to the problem of existing ways of helping multi-challenged families; specifically, to the numerous entries of various professionals into the family. Every professional is primarily focused on solving the part of the problem that has prompted him/her to enter into collaboration with the family. Bouwkamp and Bouwkamp (p. 301) address the problem of dispersion in the process of support and help to multi-challenged families with the metaphor of a broken car that is repaired part by part in different workshops, in the hope that the problem will be solved when the car is reassembled. Various professionals who deal with family problems in different areas, but separately, can represent a burden for the family, who too often remain without the support and help needed.

This emphasis is closely connected to the basic starting point of the authors' approach of being personally engaged as a professional when collaborating with families. The importance of the relationship established with people in the process of support and help is shifted to the fore. The reader can perceive a respectful attitude towards family members and a deep trust in people, who are competent and full of resources to achieve the desired changes. The professional also brings new experiences to the relationship, which can only materialise here and now, when we establish a personal relationship with people. In order to provide new learning about how to care for oneself and for each other, as well as for the relationship, it is important that the professional, through ongoing self-reflection, acts on the basis of taking his/her needs into account, as this will present the model for the interlocutor.

The basic thematic emphasis of the book is fresh. The authors do not write about so-called disorders, diagnosis, etc., which can quickly lead us in the wrong direction: we begin to silence the siren indicating a fire, while the house burns to the ground. They stress that the symptoms are not the focus of the fire, but a warning of its existence (p. 17). Patterns of family interactions are foregrounded, as they can lead to the development of many of the problems that cause people to seek help. Special value is added to the book with the segments of stories in which the authors illustrate the theory and show possible ways of acting through practical examples.

In three thematic sections, the book is structured in eleven chapters, with an appendix entitled Towards a Pattern-Oriented Model of Intervision as a support for team intervision based on the premises of the book. The Slovenian translation begins with a foreword by the Slovenian editor, which importantly bridges the Dutch book with Slovenian context. The challenges of adjustments and of the search for appropriate terminology for the Slovenian translation are also presented in this introduction. The editor's footnotes throughout the book, 
which extend understanding and help to put the Dutch authors' writing in the Slovenian context, are also a great help for the reader.

In the first part of the book, entitled Patterns of Interactions in Families, the authors illustrate possible patterns of interactions between parents and children, which are formed on a synthesis of the theoretical starting points of attachment theory and a model of structural analysis of social behaviour, supported by rich practical experiences of collaboration with families.

The second part of the book, entitled Patterns in the Processes of Support and Help, is structured in three chapters, in which the authors present patterns of interactions between professionals and people who need support or help. Throughout the chapters, there is a detailed description of patterns of interactions that can be provoked by the person in need or by the professional, while possible professional traps are presented along with support for professionals to overcome these traps.

Patterns in the Field of Psychosocial Acting is the title of the third, most extensive part of the book. Through six chapters, behavioural patterns are presented that may be encountered in different areas of psychosocial acting. Various areas are covered: so-called outpatient treatment, the mental health field, child and adolescent protection, and institutional care for children and adolescents. In all of the chapters, the authors work from an interdisciplinary approach aimed at connecting the various professions that can contribute their share to the desired changes in people's lives. The eleventh and final chapter offers guidance for ongoing, effective help to overcome the problem of families and professionals being caught in the vicious circle that inevitably leads to paralysing and suspending the processes of support and help (p. 313).

The publication of the book Blizu doma in Slovenian is very welcome. It must have been a challenging task for the translator Stana Anželj to adapt the terminology to the Slovenian context. In several parts of the book, the translator and the editor have successfully contributed to the careful development of language that reflects the contemporary understanding of concepts of help. In some parts, however, the terminology is somehow still rigid and for the language-sensitive reader may raise questions about a consistent understanding of the role of the professional as a respectful co-creator of help with people, as opposed to possessing the truth and the right answers for a person (e.g., the denomination of healthy and unhealthy adults and children). Nonetheless, this undoubtedly substantive thematic contribution offers an opportunity for further discussion and the development of a contemporary, collaborative understanding of processes of support and help, and with this the development of related terminology. 
I understand Blizu doma as a professionally and personally engaged invitation for the reader to step closer to home in the processes of support and help or in personal life (being personally engaged in a collaborative community supports people to co-create the desired outcomes and enables them to begin to write new, desired personal stories). The merit of the book lies in the fact that the writing does not merely offer an invitation; it is a work that theoretically and practically shows possible ways and suggests possible answers to the often overlooked question of the helping professions: how to act. 